\title{
Preliminary Study of the Mechanical Properties of Hybrid Fibres Reinforced Unsaturated Polyester Composites
}

\author{
Chek Shin Tan, ${ }^{1}$ Ming Yeng Chan, ${ }^{2 *}$ and Seong Chun Koay ${ }^{3}$ \\ ${ }^{1}$ Imperium International College, Centre for Engineering Programmes, \\ Kuala Lumpur, Malaysia \\ ${ }^{2}$ Faculty of Engineering and Technology, Tunku Abdul Rahman University College, \\ Kuala Lumpur, Malaysia \\ ${ }^{3}$ School of Computer Science and Engineering, Faculty of Innovation and Technology, \\ Taylor's University - Lakeside Campus, Subang Jaya, Selangor, Malaysia \\ "Corresponding author: chanmingyeng@hotmail.my
}

Published online: 25 November 2021

To cite this article: Tan, C. S. et al. (2021). Preliminary study of the mechanical properties of hybrid fibres reinforced unsaturatad polyester composites. J. Phys. Sci., 32(3), 45-59. https://doi.org/10.21315/jps2021.32.3.4

To link to this article: https://doi.org/10.21315/jps2021.32.3.4

\begin{abstract}
This research project investigates the mechanical properties of the corn husk fibre reinforced unsaturated polyester composite (CHFPC) and hybrid fibre (corn husk/flax) reinforced unsaturated polyester composite (HFPC) at different fibre orientations. The tensile and flexural properties of CHFPC and HFPC were manipulated by the different degrees of fibre orientations of $0^{\circ}, 45^{\circ}$, and $90^{\circ}$. Both CHFPC and HFPC with $0^{\circ}$ of fibre orientation had the highest tensile strength and flexural strength. Moreover, the tensile and flexural modulus of specimens with $0^{\circ}$ orientation had the highest result compared to $45^{\circ}$ and $90^{\circ}$ orientations. However, for the elongation at break during tensile testing, $0^{\circ}$ orientation had the highest strain, more than unsaturated polyester (UPR) and other composites. The tensile and flexural strengths of HFPC specimens with $0^{\circ}$ fibre orientation were higher than that of CHFPC. Besides, the tensile modulus and flexural modulus of HFPC also increased as compared to CHFPC. The elongation at break of HFPC for tensile testing had the highest strain compared to CHFPC. The results showed that the mechanical properties of the hybrid fibre composite performed better compared to the single fibre composite. Moreover, the corn husk fibre (CHF) and flax fibre (FF) acted as reinforcements to enhance the mechanical properties of the UPR composites.
\end{abstract}

Keywords: corn husk fibre, flax fibre, unsaturated polyester, fibre orientation, composites 


\section{INTRODUCTION}

Pollution related to environmental issue has become a significant topic around the world. Increased construction causes deforestation of rain forest and wildlife, which contribute to environmental issues, especially greenhouse effects, global warming, and the thinning of the atmosphere due to fuel burning and deforestation. Environmental pollution can be a threat to mankind as clean sources of air, food, and water are vital to human health. As a result, people should pay more attention, interest, and take faster action to save the environment and protect mother nature. ${ }^{1}$ There are a lot of ways to reduce pollution and one of the many ways is to adopt the $3 \mathrm{R}$ waste programme, which is the Reduce, Reuse and Recycle waste programme. Another way is to replace synthetic fibres (e.g., glass fibre) composites with agriculture waste in the fabrication of polymer composites..$^{2-4}$

In addition, agricultural development to feed people has created agricultural waste from corn, flax, vegetables, oil palm and fruits. The agricultural waste is increasing annually and if these environmentally friendly materials can be reused, pollution can be reduced by reducing the amount of waste produced from agricultural industries. Therefore, global awareness towards the reuse of agriculture fibres and environmental-friendly materials has been studied by many researchers. ${ }^{5-8}$ Furthermore, environmental impacts of agriculture such as agricultural waste, land and water degradation, deforestation, climate change, soil degradation, and biodiversity loss have been reduced by utilising valuable agricultural wastes found in polyester composites. ${ }^{9}$ Therefore, corn husk fibre (CHF) and flax fibre (FF) have been used as natural reinforcement fibres to be studied in this research.

CHF is a renewable resource and it consists of high content of lignocellulosic fibre (e.g., $44.5 \%$ hemicellulose, $38.2 \%$ cellulose, $6.6 \%$ lignin, $2.8 \%$ ash, and $1.9 \%$ protein).${ }^{10}$ Furthermore, corn husks fibre has outstanding strength, high elongation, moderate durability, and ready biodegradability. ${ }^{10}$ Meanwhile, FF is most widely utilised as renewable bio-fibres. According to Yan et al., flax is also one of the first fibres to be extracted, spun, and woven into textiles. ${ }^{11}$ Therefore, these two fibres can be used as cheap, sustainable, renewable, and easily found natural fibre reinforced materials to produce hybrid natural fibre reinforced polyester composites.

The natural fibre reinforcement material is usually harder, stronger, and stiffer than the matrix and exhibits a diversity of physical and mechanical characteristics. ${ }^{12}$ The purposes of composites are to obtain a more desirable combination of properties such as low density, high strength and stiffness as well as good shear properties. ${ }^{13}$ However, the hybrid fibres polymer composite will greatly enhance mechanical properties compared to single fibre reinforcement material polymer composite due 
to the different properties of reinforcement materials. ${ }^{14}$ From the study by Idicula et al., it is claimed that banana and sisal fibres act as reinforcement in polyester composite and then are hybridised with glass fibre to get good mechanical properties. ${ }^{15}$ Besides that, the processes to prepare hybrid polymer composite is relatively inexpensive, producing by-products that are lightweight as well as corrosion resistant. ${ }^{16}$ Generally, the hybrid polymer composite is applied in various structural components such as aircraft, transport vehicle, and civil and automotive structures. ${ }^{17,18}$

Therefore, unsaturated polyester (UPR) was combined with CHF to produce corn husk fibre reinforced polyester composite (CHFPC). Besides, UPR with CHF and $\mathrm{FF}$ are combined to produce hybrid fibre polyester composite (HFPC) via the vacuum infusion technique. The objectives of this research are to study the effect of different fibre orientations on the mechanical properties of CHFPC as well as to evaluate the mechanical properties of HFPC. In addition, the mechanical properties behaviour of fibre reinforced polyester composite can be defined by the orientation of fibre such as $0^{\circ}, 45^{\circ}$, and $90^{\circ}$. The tensile and flexural testing results are shown to compare the mechanical properties between CHFPC and HFPC.

\section{EXPERIMENTAL}

\subsection{Materials}

UPR resin and Butanox hardener were supplied by Taurenz Resources Sdn. Bhd., Kedah, Malaysia. The corn husk was collected from a wet market in Kuala Lumpur, Malaysia, and the CHF was extracted from corn husk through the water retting process. Besides, the unidirectional $\mathrm{FF}$ was purchased from Fiber Care Enterprise, Kuala Lumpur, Malaysia. The acrylic binder resin (Acrodur DS 3530) was purchased from BASF, Kuala Lumpur, Malaysia.

\subsection{Water Retting Method to Extract CHF from Corn Husk}

The CHF was extracted via a simple water retting method. Firstly, the corn husk was collected, cleaned and soaked in water for two weeks to go through the microbacterial degradation process. After two weeks, the corn husk became soft and the fibre was easily extracted by combing with a brush to take out the remaining particles from the surface of the fibre. After extracting the fibre from the corn husk, the fibre was then oven-dried at $70^{\circ} \mathrm{C}$ for $24 \mathrm{~h}$. Figure 1 explains the water retting steps of corn husk. 


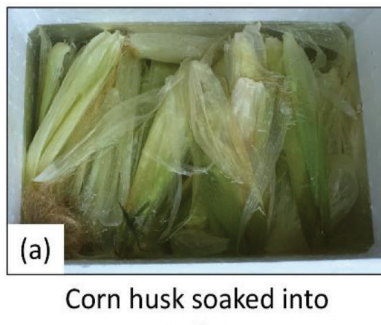

water

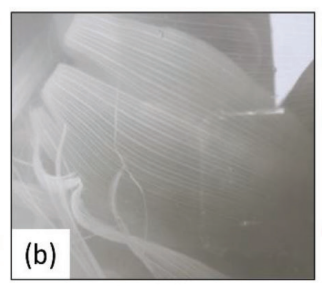

Corn husk became soft

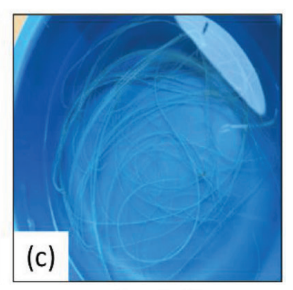

Corn husk fibre extracted by combing with the brush

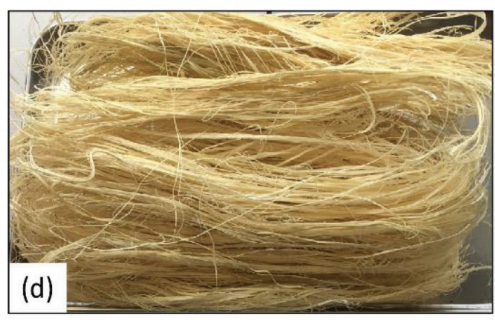

Dried corn husk fibre

Figure 1: Water retting method of CHF.

\subsection{Preparation of Single and Hybrid Fibres Mats}

Twenty grams of the CHF was soaked into the Acrodur binder solution with a ratio of $1: 100$ and oriented unidirectionally before being re-dried at $70^{\circ} \mathrm{C}$ for $24 \mathrm{~h}$, as shown in Figure 2(a). After $24 \mathrm{~h}$ of oven drying, the fibres [Figure 2(b)] were put through a compression moulding process at a temperature of $180^{\circ} \mathrm{C}$. The process took a total of $15 \mathrm{~min}$ to complete including $5 \mathrm{~min}$ of compression holding time, and 10 min cooling process. The same procedures were used to prepare a hybrid fibre mat with $10 \mathrm{~g}$ of $\mathrm{CHF}$ and another $10 \mathrm{~g}$ of FF. After compressing, the fibres formed a unidirectional fibre mat. The unidirectional hybrid fibres were produced by placing $10 \mathrm{~g}$ of $\mathrm{CHF}$ at the top and another $10 \mathrm{~g}$ of the FF placed at the bottom, as shown in Figure 2(c). 


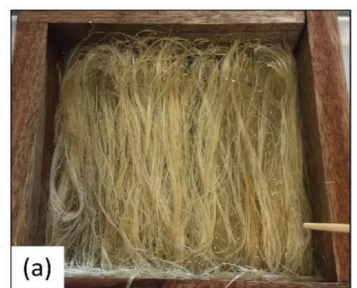

Corn husk fibre soaked into binder solution

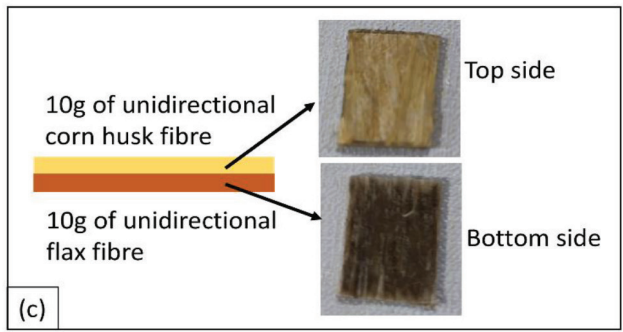

Figure 2: (a) CHF soaking in the binder solution, (b) dried unidirectional CHF, and (c) hybrid fibres.

\subsection{Preparation of Single and Hybrid Fibre Reinforced Polyester Composites}

The UPR was used as a polymer matrix in the CHFPC and hybrid fibre reinforced unsaturated polyester composite (HFPC). Firstly, all the materials and apparatus such as CHF mats, hybrid CHF/FF mats, UPR resin, Butanox hardener, vacuum machine, nylon vacuum bagging film, peel ply, breathable fabric, sealant tacky tape, acrylic mould, tube, were prepared and set up [refer to Figure 3(a)]. Next, the UPR resin was mixed with $1 \%$ of hardener to produce the UPR solution. The fibre mat was impregnated with UPR by vacuum infusion technique, as shown in Figure 3(b).

The polyvinyl alcohol (PVA) release agent was first applied to the acrylic mould. Then, the fibre mat was applied to the mould. After that, the peel ply followed by breathable fabric was placed on the fibre mat. The vacuum bag was stacked to the mould using sealant tacky tape. Next, the vacuum pressure was switched on at approximately -0.5 bar allowing the UPR solution to infuse into the fibre mat. The vacuum pressure was stopped when the fibre mat was fully soaked by the resin and the UPR composite proceeded the curing process at room temperature 
for $24 \mathrm{~h}$. Finally, the CHF reinforced polyester composites were prepared using the same steps to produce the hybrid CHF/FF reinforced polyester composites. All composites were prepared with a ratio of 55:45 (UPR: fibre).
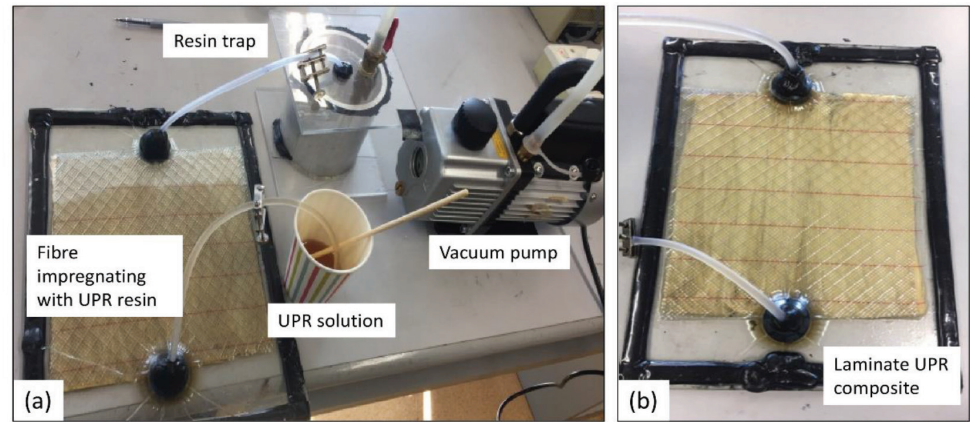

Laminate structure of UPR composite

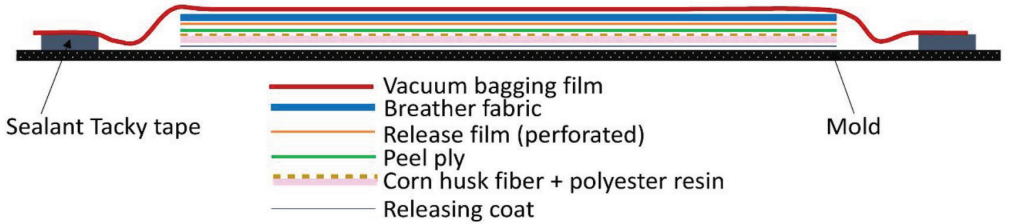

Figure 3: (a) Vacuum infusion method and (b) laminated UPR composite.

\section{$2.5 \quad$ Testing}

\subsubsection{Tensile test}

A tensile test was used to determine the tensile strength, tensile modulus, and the elongation of CHFPC and HFPC using the VICTOR (Ho Chi Minh, Vietnam) material testing equipment (model VEW2302). The process of this test included applying tension force by pulling apart the composite specimens until they failed or broke. The tensile properties response to the stress was recorded to compare between different orientations of CHFPC and HFPC such as $0^{\circ}, 45^{\circ}$, and $90^{\circ}$. Besides, $10 \mathrm{kN}$ of load and $30 \mathrm{~mm} / \mathrm{min}$ of cross-head speed were applied for tensile test. The tensile test was performed at room temperature and according to ASTMD 638. At least 10 tensile specimens from each fibre orientation of the polyester composite were tested.

\subsubsection{Flexural test}

Flexural testing was performed to determine the flexural strength and flexural modulus of CHFPC and HFPC using the VICTOR material testing equipment (model VEW2302). The process of this testing applied the load to the centre of the 
composite specimens by the loading nose. The specimens were placed horizontally over two points of contact known as lower support span until they reached fibre break or fail. The flexural test was carried out according to the ASTMD 790. A $10 \mathrm{kN}$ of load and $30 \mathrm{~mm} / \mathrm{min}$ of cross-head speed were applied for the flexural test. The flexural properties results were compared between UPR and the different orientations $\left(0^{\circ}, 45^{\circ}\right.$, and $\left.90^{\circ}\right)$ of CHFPC and HFPC.

\subsubsection{Statistical analysis}

The analysis of variance (ANOVA) of tensile and flexural properties results were measured by Microsoft Excel 2013. ANOVA was carried out to measure the significance in the difference between means and to detect the significant differences in the single and hybrid fibre reinforced UPR composites. The significance level was set to $p \leq 0.05$.

\section{RESULTS AND DISCUSSION}

\subsection{Tensile Properties}

Figure 4 illustrates the stress-strain curves of neat UPR, CHFPC, and HFPC. Based on Figure 4, it can be seen that HFPC underwent the largest plastic deformation as compared to neat UPR and CHFPC. The increase in strengths can be observed as the specimens began to strain to harden until reaching the point of failure. Besides, the HFPC demonstrated relatively higher strength, stiffness, ductility, and toughness as compared to neat UPR and CHFPC. 


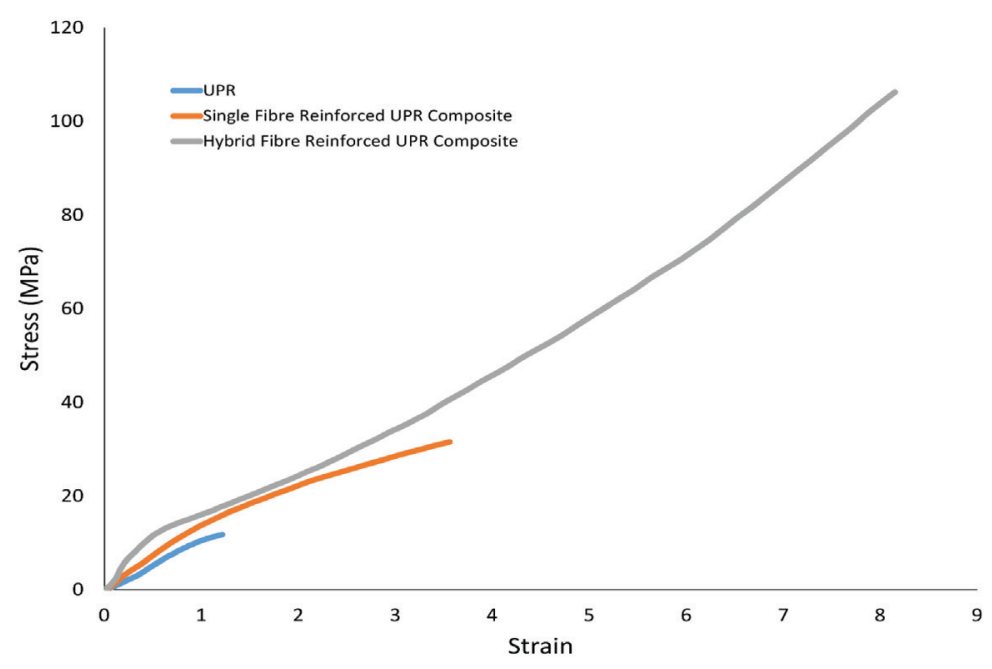

Figure 4: Stress-strain curves of UPR, CHFPC, and HFPC.

Moreover, the tensile strengths were determined for the UPR and different CHF orientations of CHFPC. Based on Figure 5, the tensile strength of all the CHFPC is higher than UPR due to CHF acting as reinforcement in this UPR composite with high stress transfer efficiency from matrix to fibre. Furthermore, the CHFPC with $0^{\circ}$ orientation showed the greatest tensile strength compared to UPR and others UPR composites. This is due to the reason that the fibres are continuously aligned parallelly along the longitudinal axis to the loads. Therefore, the fibres support each other to withstand the load or force applied. However, the CHFPC at $90^{\circ}$ of $\mathrm{CHF}$ orientation had the lowest tensile strength as compared to $0^{\circ}$ and $45^{\circ}$. Moreover, the tensile strength of CHFPC that orientated at $45^{\circ}$ was slightly higher than $90^{\circ}$. A minimum strength is obtained when the fibres orientated at $90^{\circ}$ because the fibres were perpendicularly aligned along the longitudinal axis to the loads. Later, the fibres tend to not support each other and were prone to breaking easily as well, 
resulting in failure. According to Retnam et al., the tensile strength of the composite materials is strongly affected by different fibre orientations in the composite. ${ }^{13} \mathrm{~A}$ similar finding was recorded by Lasikun et al. It was informed that the high-density polyethylene (HDPE)/Zalacca Midrib fibre composites showed the highest tensile strength at the fibre orientation of $0^{\circ}$ since the direction of fibre was parallel to the loading direction. ${ }^{19}$ However, the lowest tensile strength occurred at the fibre orientation of $90^{\circ}$. This is because the fibre was perpendicularly orientated to the loading direction that occurred on the composites of the fibre orientation from $15^{\circ}$ to $90^{\circ} .{ }^{19}$

According to Figure 5, the HFPC showed higher tensile strength than UPR and CHFPC. The hybrid CHF/FF fibre provided better tensile strength $(p<0.05)$ to UPR composite than CHF. This result was aligned with the finding from Retnam et al. They found that the tensile strength of hybrid bamboo/glass fibre polymer composite was higher than bamboo fibre reinforced polymer composites. ${ }^{13}$ Accordingly, the mechanical properties of the composite can be enhanced by two or more different types of fibres in a single matrix, leading to hybrid composites with greater mechanical properties. ${ }^{13}$

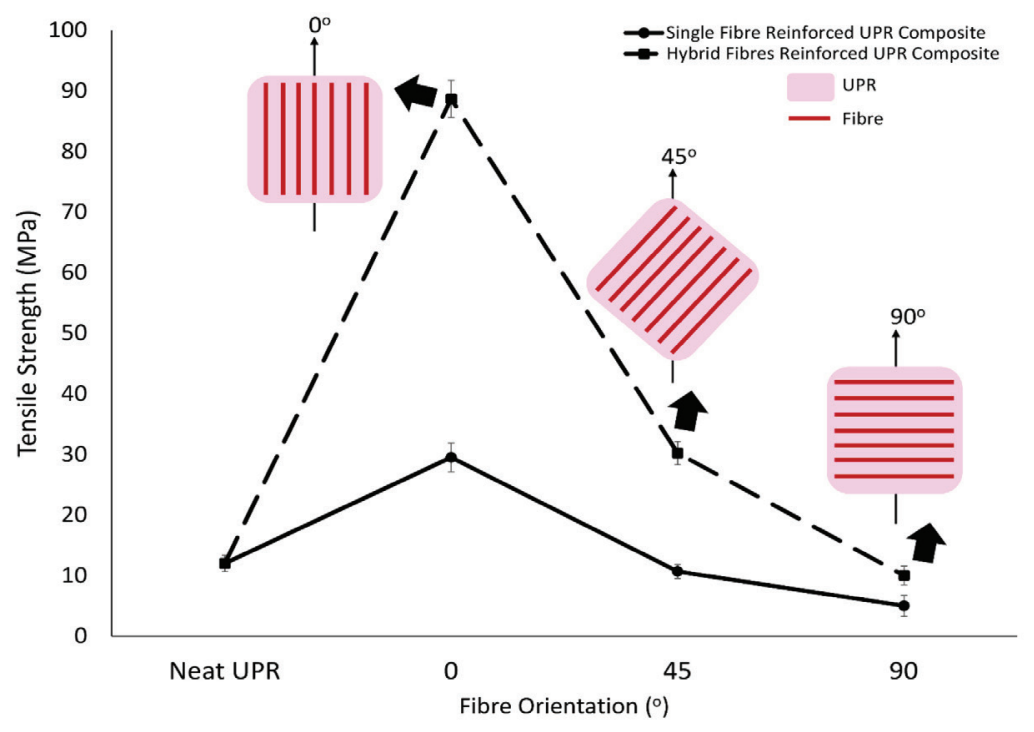

Figure 5: Tensile strength of UPR, CHFPC, and HFPC.

The proposed possible failures of corn husk fibre reinforced unsaturated polyester at different fibre orientations as shown in Figure 6. Based on Figure 6, the results of the effect of fibre orientation of CHFPC recognised that the $0^{\circ}$ of fibre orientation had the greatest tensile properties compared to $45^{\circ}$ and $90^{\circ}$. This is because the fibre composite orientated at $0^{\circ}$ was in longitudinal loading and would support each 
other to withstand higher loads or forces. However, fibre composites orientated at $90^{\circ}$ was in transverse loading while $45^{\circ}$ was in slant. Therefore, the fibres did not support each other when the tensile loads were applied.

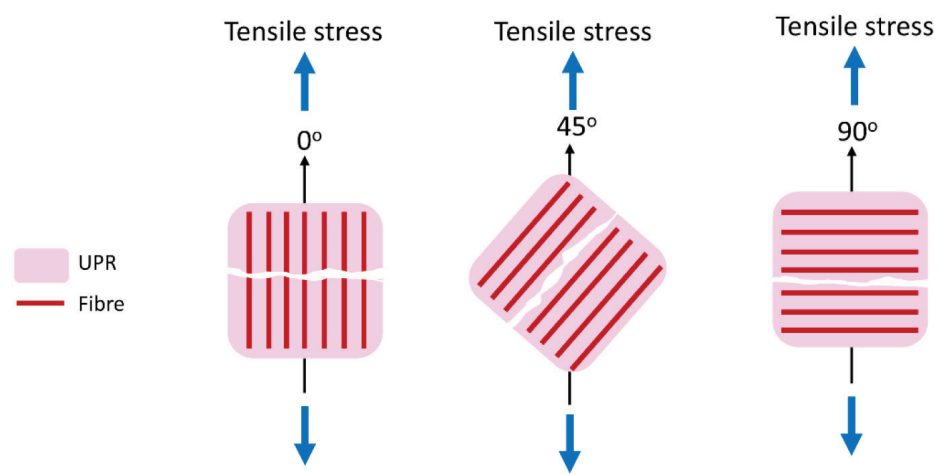

Figure 6: Proposed possible failures of CHF reinforced UPR at fibre orientations of $0^{\circ}$, $45^{\circ}$, and $90^{\circ}$.

In addition, Figure 7 shows the tensile modulus of UPR and different fibre orientations of CHFPC. The higher the tensile modulus, the higher the stresses required to induce elastic deformation. UPR composites had higher tensile modulus compared to neat UPR. This is due to the incorporation of the high stiffness CHF into UPR composites. According to Wong and Chan, the increment in stiffness of the composite was affected by the presence of high stiffness natural fibres. ${ }^{20}$ Therefore, UPR composites needed higher load to induce elastic deformation. Furthermore, it can be observed that the tensile modulus had slightly decreased from fibre orientations of $0^{\circ}$ to $90^{\circ}$ due to the same amount of the fibre that was incorporated into the UPR composites. Nevertheless, the tensile modulus of the hybrid UPR composite had significantly increased $(p<0.05)$ as compared to single fibre reinforced UPR composites due to the presence of two different fibres in the composite. 


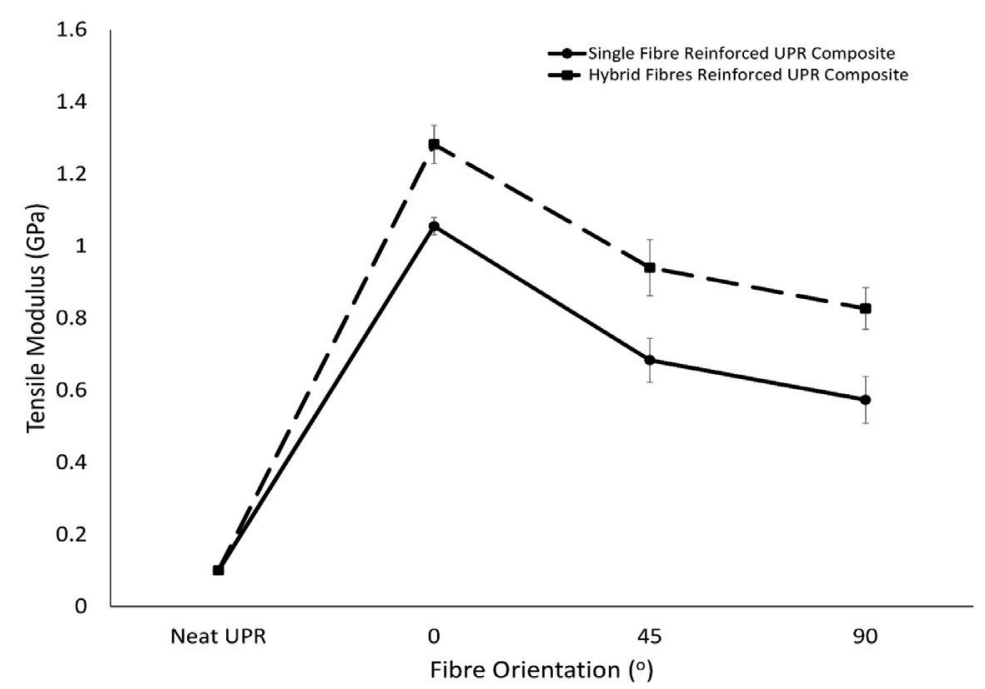

Figure 7: Tensile modulus of UPR, CHFPC, and HFPC.

Besides, the higher the elongation at the break, the length became longer than the original length, which meant higher ductility. Based on Figure 8, the elongation at break of CHFPC was higher than UPR. This might be due to the moisture content in CHF which provided plasticised effect and improved the elongation at break of UPR composites. From Figure 8, the elongation at break had decreased at different $\mathrm{CHF}$ orientations from $0^{\circ}$ to $90^{\circ}$. In addition, the hybrid $\mathrm{CHF} / \mathrm{FF}$ had enhanced $(p \geq 0.05)$ the elongation of UPR composite and the HFPC had shown higher elongation at break as compared to CHFPC. This is because CHF and FF had enhanced the elongation property of the UPR composites. 


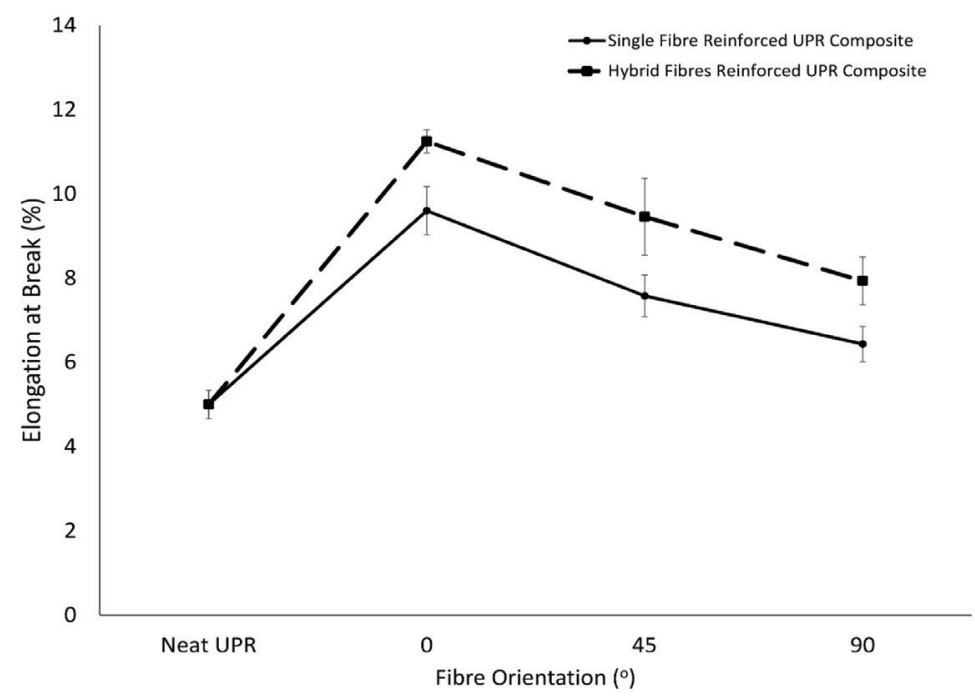

Figure 8: Elongation at break of UPR, CHFPC, and HFPC.

\subsection{Flexural Properties}

Based on Figure 9(a), the flexural strengths of CHFPC that had orientated at $45^{\circ}$ and $90^{\circ}$ were slightly weaker than UPR. However, the CHFPC that orientated at $0^{\circ}$ was the best option to apply because it had improved the flexural strength of the composite, which is greater than UPR composites. The addition of the hybrid fibre showed an improvement $(p<0.05)$ in flexural strength as compared to single fibre reinforced UPR composite.

Figure 9(b) shows a slight decrease of the flexural modulus at different orientations of CHFPC from $0^{\circ}$ to $90^{\circ}$. The higher the flexural modulus, the stiffer and lower deflection for the materials. HFPC has greater $(p<0.05)$ flexural modulus as compared to CHFPC. The result of flexural properties of UPR composites aligned with the result of the tensile properties.

Another study, by Ezema et al., claimed that the composite strength in the longitudinal direction $\left(0^{\circ}\right)$ was higher than the transverse direction $\left(90^{\circ}\right)$ or other orientations like $45^{\circ} .{ }^{21}$ Consequently, the UPR composites with a fibre orientation of $0^{\circ}$ showed better mechanical properties as compared to UPR composite with fibre orientation from $45^{\circ}$ to $90^{\circ}$. 


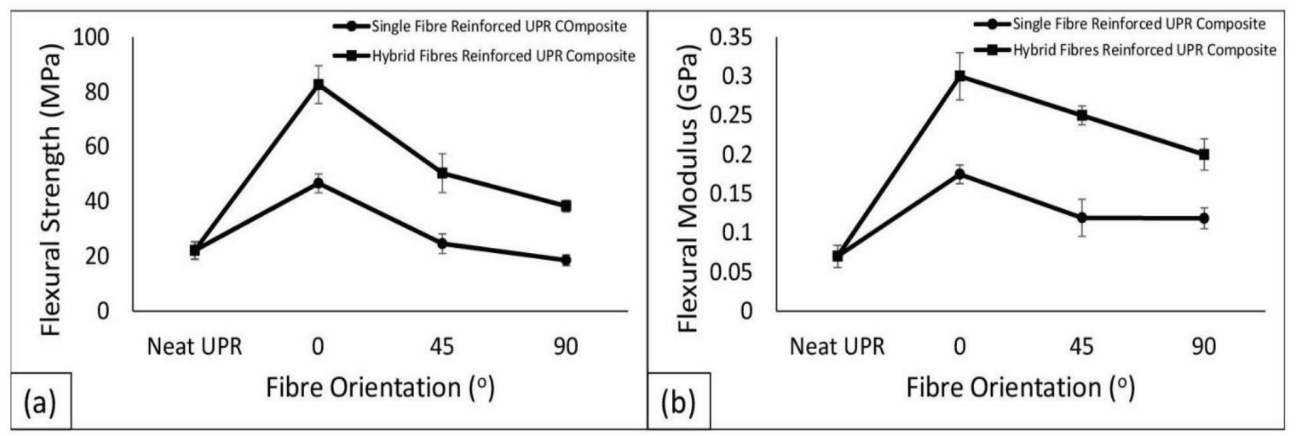

Figure 9: (a) Flexural strength and (b) flexural modulus of UPR, CHFPC, and HFPC.

\section{CONCLUSION}

Derived from the results, different fibre orientations of CHFPC showed that the specimens with $0^{\circ}$ fibre orientation composites had the highest tensile strength and flexural strength compared to $45^{\circ}$ and $90^{\circ}$. It proved that the different orientations of CHFPC had affected the tensile and flexural properties of the UPR composites. The CHFPC that orientated at $0^{\circ}$ showed the greatest tensile strength and flexural strength due to the fibres that were oriented in longitudinal direction and the fibres had supported each other, hence, it would withstand higher loads while testing. On the other hand, $90^{\circ}$ of fibre orientation had the weakest tensile strength and flexural strength because the fibres were oriented in transverse directions, which is perpendicular to the loading conditions and not in support of each other. As a result, the $90^{\circ}$ of fibre orientation in composite specimens will break easily or fail easily. Other than that, the hybrid fibre had enhanced the mechanical properties of the UPR composite because HFPC had two different fibre materials combined, which was stronger in mechanical properties than one fibre composite material. Therefore, the HFPC showed better mechanical properties than the CHFPC.

\section{ACKNOWLEDGEMENTS}

The corresponding author would like to thank the co-authors for sharing their knowledge in this research project and the Imperium International College for providing the materials and equipment to complete the research project. 


\section{REFERENCES}

1. Karthik Babu, N. B. et al. (2020). Thermal and mechanical behavior of the coir powder filled polyester micro-composites. J. Nat Fibers., 17(7), 1058-1068. https://doi.org/10.1080/15440478.2018.1555503

2. Wambua, P., Ivens, J. \& Verpoest, I. (2003). Natural fibres: Can they replace glass in fibre reinforced plastics? Compos. Sci. Technol., 63(9), 1259-1264. https://doi. org/10.1016/S0266-3538(03)00096-4

3. Omrani, F. et al. (2017). Mechanical properties of flax-fibre-reinforced preforms and composites: Influence of the type of yarns on multi-scale characterisations. Compos. Part A: Appl. Sci. Manufac., 93, 72-81. https://doi.org/10.1016/j. compositesa.2016.11.013

4. Pickering, K. L., Efendy, M. A. \& Le, T. M. (2016). A review of recent developments in natural fibre composites and their mechanical performance. Compos. Part A: Appl. Sci. Manufac., 83, 98-112. https://doi.org/10.1016/j.compositesa.2015.08.038

5. Pao, C. N. Z. \& Yeng, C. M. (2019). Properties and characterization of wood plastic composites made from agro-waste materials and post-used expanded polystyrene foam. J. Thermoplast. Compos. Mater., 32(7), 951-966. https://doi. org/10.1177/0892705718772877

6. Ling, S. L. et al. (2019). Wood plastic composites produced from postconsumer recycled polystyrene and coconut shell: Effect of coupling agent and processing aid on tensile, thermal and morphological properties. Polym. Eng. Sci., 60(1), 202-210. https://doi.org/10.1002/pen.25273

7. Nanthakumar, K., Yeng, C. M. \& Chun, K. S. (2020). Tensile and water absorption properties of solvent cast biofilms of sugarcane leaves fibre-filled poly (lactic) acid. J Thermoplast. Compos Mater., 33(3), 289-304. https://doi. org/10.1177/0892705718805526

8. Chan, M. Y. \& Koay, S. C. (2019). Biodegradation and thermal properties of crosslinked chitosan/corn cob biocomposite films by electron beam irradiation. Polym. Eng. Sci., 59(S1), E59-E68. https://doi.org/10.1002/pen.24854

9. Islam, M. et al. (2020). The influence of fibre orientation and chemical treatment on the performance of unsaturated polyester/chrysanthemum stem fibre composites. Polym. Polym. Compos. https://doi.org/10.1177/0967391120954067

10. Chun, K. S. et al. (2018). Wood plastic composites made from corn husk fiber and recycled polystyrene foam. J. Eng. Sci. Technol., 13(11), 3445-3456.

11. Yan, L., Chouw, N. \& Jayaraman, K. (2014). Flax fibre and its composites - A review. Compos. Part B: Eng., 56, 296-317. https://doi.org/10.1016/j. compositesb.2013.08.014

12. Satyanarayana, K. G. et al. (1990). Natural fibre-polymer composites. Cem. Concr. Compos., 12(2), 117-136. https://doi.org/10.1016/0958-9465(90)90049-4

13. Retnam, B. S. J., Sivapragash, M. \& Pradeep, P. (2014). Effects of fibre orientation on mechanical properties of hybrid bamboo/glass fibre polymer composites. Bull. Mater. Sci., 37(5), 1059-1064. 
14. Kalaprasad, G., Joseph, K. \& Thomas, S. (1997). Influence of short glass fiber addition on the mechanical properties of sisal reinforced low density polyethylene composites. J. Compos. Mater., 31(5), 509-527. https://doi. org/10.1177/002199839703100504

15. Idicula, M. et al. (2005). Dynamic mechanical analysis of randomly oriented intimately mixed short banana/sisal hybrid fibre reinforced polyester composites. Compos. Sci. Technol., 65(7-8), 1077-1087. https://doi.org/10.1016/j. compscitech.2004.10.023

16. Mohammed, L. et al. (2015). A review on natural fiber reinforced polymer composite and its applications. Int. J. Polym. Sci., 2015, 1-15. https://doi. org/10.1155/2015/243947

17. Kureemun, U. et al. (2018). Effects of hybridization and hybrid fibre dispersion on the mechanical properties of woven flax-carbon epoxy at low carbon fibre volume fractions. Compos. Part B: Eng., 134, 28-38. https://doi.org/10.1016/j. compositesb.2017.09.035

18. Brahim, S. B. \& Cheikh, R. B. (2007). Influence of fibre orientation and volume fraction on the tensile properties of unidirectional Alfa-polyester composite. Compos. Sci. Technol., 67(1), 140-147. https://doi.org/10.1016/j.compscitech.2005.10.006

19. Lasikun, et al. (2018). Effect of fiber orientation on tensile and impact properties of Zalacca Midrib fiber-HDPE composites by compression molding. AIP Conf. Proc., 1931(1), 1-5. https://doi.org/10.1063/1.5024119

20. Wong, J. Y. M. \& Chan, M. Y. (2018). Influence of bleaching treatment by hydrogen peroxide on chitosan/durian husk cellulose biocomposite films. Adv. Polym. Technol., 37(7), 2462-2469. https://doi.org/10.1002/adv.21921

21. Ezema, I. C. et al. (2014). Effect of surface treatment and fiber orientation on the tensile and morphological properties of banana stem fiber reinforced natural rubber composite. J. Miner. Mater. Char. Eng., 2(3), 216-222. http://doi.org/10.4236/ jmmce.2014.23026 